\title{
Reflexões sobre o Programa de Pós-Graduação em História Social — trinta anos
}

\section{RESUMO}

Em julho de 2012, em celebração dos trinta anos de criação do Programa de Pós-Graduação em História Social da Universidade Federal do Rio de Janeiro, o Comitê Editorial de Topoi solicitou a Francisco Falcon que escrevesse uma narrativa acerca das origens e do desenvolvimento do programa. Esse texto foi, a seguir, enviado a José Murilo de Carvalho e Marieta de Moraes Ferreira, que por sua vez desenvolveram suas próprias reflexôes a partir das questôes propostas por Francisco Falcon. Publicamos aqui este diálogo entre três professores que não só participaram da construção do PPGHIS, mas que ajudaram a desenvolver os estudos de pós-graduação em história no Brasil.

Palavras-chave: história da educação; universidades; historiografia; memória.

\section{ABSTRACT}

In July 2012, in celebration of the 30th anniversary of the Graduate Program in Social History of the Federal University of Rio de Janeiro, Topoi's Editorial Committee asked Francisco Falcon to write a short narrative about the origins and development of the program. This text was then sent to José $\mathrm{Mu}-$ rilo de Carvalho and Marieta de Moraes Ferreira, who wrote their own reflexive memories drawing from the themes proposed by Francisco Falcon. We publish here this conversation among three scholars who not only took part in the building of PPGHIS, but who also helped to develop History graduate studies throughout Brazil.

Keywords: history of education; university; historiography; memory. 


\title{
O Programa de Pós-Graduação em História Social do IFCS/UFRJ — um ensaio de história e memória
}

\author{
Francisco José Calazans Falcon \\ Universidade Salgado de Oliveira \\ São Gonçalo, RJ, Brasil \\ prof@franciscofalcon.com.br
}

\section{Primeira parte: A Faculdade Nacional de Filosofia e a Fundaçáo do Instituto de Filosofia e Ciências Sociais}

\section{Alguns esclarecimentos prévios}

Este não é um estudo sobre a história da História na antiga Faculdade Nacional de Filosofia (FNFi), ou no Instituto de Filosofia e Ciências Sociais (IFCS) que a sucedeu a partir de 1967. ${ }^{1}$ Nosso objeto de estudo é o Programa de Pós-Graduação em História Social (PPGHIS), as circunstâncias da sua criação e as principais características que marcaram o seu desenvolvimento até o final do século XX.

Todavia, estamos convencidos de que esta história tem suas raízes mais profundas na trajetória do Curso de Graduação em História e nos acontecimentos dramáticos e decisivos que marcaram a história da FNFi ao longo das décadas de 1950 e 1960, sobretudo a última, assim como na influência que tiveram, nessa mesma época, os debates políticos e os movimentos sociais em nível nacional, as discussóes intelectuais entấo em andamento, a mobilização em favor da reforma universitária, e a organização dos docentes e discentes em história.

Por outro lado, este é também um ensaio baseado na nossa memória, ou seja, nas lembranças de muitas de nossas experiências e vivências durante as várias décadas abrangidas por esta narrativa.

Em relação ao mundo acadêmico da Faculdade Nacional de Filosofia, nossas lembranças mais antigas remontam aos anos de 1949 a 1951, quando fizemos o colegial no Curso Científico do Colégio de Aplicação da FNFi. Foi então que começamos a pensar seriamente na possibilidade de uma vida acadêmica, no estudo da história e da geografia, numa futura graduação na Faculdade Nacional de Filosofia. Naqueles tempos mágicos, como chamei aqueles anos em recente tentativa de ensaio autobiográfico, foram decisivos o estímulo e a orientação de alguns mestres inesquecíveis, a começar pela professora Marina S. Paulo de Vasconcellos.

De 1952 a 1955 cursamos a graduação da licenciatura e bacharelado em história e geografia. Habituamo-nos então à ideia de um curso voltado especificamente à formação de professores para o ensino ginasial e colegial. Não se colocava então o problema da pesquisa, nem tampouco o de um nível de estudos pós-graduados. O importante era ler, ler muito, dominar a bibliografia atualizada e a historiografia dos principais temas. Foi de acordo com tais pressupostos que aceitamos convite da professora Maria

\footnotetext{
${ }^{1}$ FERREIRA, Marieta de Moraes. Notas sobre a institucionalização dos cursos universitários de história no Rio de Janeiro. In: GUIMARĀES, Manoel Luiz Salgado (Org.). Estudos sobre a escrita da história. Rio de Janeiro: 7 Letras, 2006. p. 139-161. Este artigo é parte de um importante projeto de pesquisa da autora acerca das origens dos cursos das faculdades de filosofia, inclusive do papel de mestres franceses e da influência das circunstâncias políticas e ideológicas.
} 
Yedda Leite Linhares, da cadeira de História Moderna e Contemporânea, para com ela trabalharmos, a partir de março de 1956, como auxiliar de ensino não remunerado.

Das nossas experiências docentes a partir de então, sobretudo as maneiras como eram cumpridas as obrigações docentes nas disciplinas de História Moderna e História Contemporânea, assim como na de História Econômica Geral para o curso de geografia, resultaram dois trabalhos já publicados ${ }^{2}$ que documentam e interpretam as atividades da cadeira de História Moderna e Contemporânea, de 1956 a 1968.

\section{Antecedentes da pós-graduação}

Pensamos que seria um tanto sem sentido ignorarmos dois aspectos fundamentais dos anos de 1956 a 1968, marcos históricos daquela mesma época na qual desenvolvíamos nosso trabalho docente na FNFi: o processo histórico brasileiro, de um lado, e a dinâmica interna da cadeira de História Moderna e Contemporânea, do outro.

O processo histórico brasileiro foi por nós analisado quanto às suas principais características e tendências em dois textos distintos, ${ }^{3}$ nos quais adotamos como critério político-cronológico a distinção entre os anos de 1958-1964 e de 1964-1968-1969.

O final do governo JK, o governo de Jânio Quadros e a crise institucional que se seguiu à sua renuncia, em agosto de 1961, a crise que cercou a sucessão de João Goulart como presidente da República, primeiro em regime parlamentarista e, pouco tempo depois, em regime presidencialista, eis as principais referências que balizam, no plano político, aquele primeiro período, entre 1958 e 1964. Do nosso ponto de vista bem mais restrito, ancorado nas questóes da vida universitária, merecem ser aqui lembrados alguns pontos destinados ou não a repercussóes fundamentais a longo prazo.

\section{A. O debate sobre a questão da reforma universitária}

Retomamos aqui alguns dos marcos mais significativos desse debate porque não só ele viria a atingir a própria sobrevivência das faculdades de filosofia, como também pelo fato de que ele interessa profundamente à questão-chave desta parte do nosso trabalho: a questão da institucionalização da pós-graduação. ${ }^{4}$

\footnotetext{
${ }^{2}$ FALCON, Francisco José Calazans. A cadeira de História Moderna e Contemporânea e o ensino e a pesquisa históricas na FNFi-UB. In: MATTOS, Ilmar Rohloff de (Org.). Histórias do ensino da História no Brasil. Rio de Janeiro: Access, 1998. p. 111-134; MATTOS, Ilmar Rohloff de. História e historiografia nos anos 50 e 60 do ponto de vista da cadeira de História Moderna e Contemporânea da FNFilosofia. In: SILVA, Francisco Carlos Teixeira da et al. Escritos sobre história e educação. Homenagem à Maria Yedda Leite Linhares. Rio de Janeiro: Mauad; Faperj, 2001. p. 599-612. Esses estudos, bem como aqueles das coletâneas em que estão inseridos, constituem fontes preciosas para o conhecimento das características teórico-metodológicas, em termos de ensino, pesquisa e definiçóes temáticas de um setor dos mais representativos do ensino de graduação e pós-graduação na antiga FNFi e no atual IFCS.

${ }^{3}$ FALCON, Francisco J. Calazans. Historiografia e ensino de história em tempos de crise — 1959/1960 — 1968/1969. In: MUNTEAL FILHO, Oswaldo et al. (Org.). Tempo negro, temperatura sufocante: Estado e sociedade no Brasil do AI5. Rio de Janeiro: Editora PUC-Rio; Contraponto, 2008. p. 37-62; MUNTEAL FILHO, Oswaldo. L'historiographie brésilienne contemporaine (1958-1969). In: CROUZET, F.; ROLLAND, Denis. Pour l'histoire du Brésil. Mélanges offerts à K. de Queirós Mattoso. Paris: L'Harmatan, 2000. p. 93-108.

${ }^{4}$ Em meio a uma enorme quantidade de jornais da época por nós colecionados, publicaçôes do antigo Conselho Federal de Educação, diversos livros e artigos, demos preferência à tese de concurso ao cargo de professor titular do Departamento de Teoria e Prática de Administração Escolar apresentada pelo professor Jésus de Alvarenga Bastos à Faculdade de Educação da Universidade Federal Fluminense (UFF), em 1980, intitulada Pós-Graduação no Brasil: institucionalização e situação atual. Entendemos que o texto dessa tese está muito bem organizado, com bastante clareza e abrangência, e oferece ao leitor um panorama preciso do tema em pauta.
} 
A luta pela construção de uma autêntica universidade no Brasil remonta, pelo menos, aos anos 1920. Contra uma tradição já anacrônica de escolas isoladas, de cunho bacharelesco e profissionalizante, arregimentaram-se importantes educadores, a partir de 1924, na Associação Brasileira de Educação. Em 1932, logo após a Reforma Francisco Campos, ${ }^{5}$ o Manifesto dos Pioneiros da Educação Nacional pronunciou-se em prol de uma universidade moderna, capaz de associar ensino e pesquisa. Há muito, no Brasil, os institutos de pesquisa avançada desenvolviam-se como instituiçóes isoladas, distantes da ideia de universidade.

Apenas em 1934, com a fundação da Universidade de São Paulo, ${ }^{6}$ e, em 1935, com a criação da Universidade do Distrito Federal, ${ }^{7}$ surgiram nossas primeiras universidades modernas: ênfase na formação básica e nos estudos humanísticos, associando ensino e pesquisa e tendo nas respectivas Faculdades de Filosofia seu principal polo de referência.

A partir de 1945, com o término da Segunda Guerra Mundial e o início da redemocratizaçáo no Brasil, diversas iniciativas vieram marcar a emergência de novas maneiras de pensar a universidade, a pesquisa e a pós-graduação. Em 1946, a então Universidade do Brasil (UB) introduziu o doutorado na Faculdade de Filosofia, ao mesmo tempo que em seu estatuto, aprovado naquele mesmo ano, o artigo 71 incluía o termo pós-graduação para designar uma nova modalidade de cursos superiores. ${ }^{8}$

Fundada em 1948, a Sociedade Brasileira para o Progresso da Ciência (SBPC) logo assumiu uma posição de liderança em prol de mudanças radicais e urgentes na estrutura e funcionamento das universidades. Enquanto correntes mais pragmáticas reivindicavam a criação de novos e mais modernos cursos de especialização e aperfeiçoamento a fim de atender às demandas de um mercado profissional em expansão, ganhava força na SBPC a chamada corrente nacionalista, com uma visão humboldtiana da universidade, ou seja, da institucionalização da pesquisa e do ensino pós-graduado na própria universidade.

Em 1951, foi criado o Conselho Nacional de Pesquisas (CNPq), atual Conselho Nacional de Desenvolvimento Científico e Tecnológico, e, alguns meses mais tarde, foi criada a Campanha de Aperfeiçoamento de Pessoal de Nível Superior (Capes), atual Fundaçáo Capes. Agentes principais do processo de criação dessas novas agências de fomento, Alvaro Alberto e Anisio Teixeira, respectivamente, criaram as bases de uma estrutura cuja expansão se tornaria fundamental, nos anos vindouros, para o fomento à pesquisa e a formação e aperfeiçoamento dos docentes pesquisadores ligados às universidades e institutos de pesquisa.

Ao longo da década de 1950, sobretudo na era do desenvolvimentismo de JK, surgiram algumas iniciativas voltadas para a criação de institutos autônomos de pesquisa, inclusive na área das ciências humanas. No entanto, os debates principais estiveram então concentrados nas discussóes sobre a nova Lei de Diretrizes e Bases da Educação Nacional (LDBEN), afinal sancionada em dezembro de 1961, e sobre a criação da Universidade de Brasília, criada nesse mesmo mês. A LDBEN estabeleceu finalmente a oferta de cursos de pós-graduação nos estabelecimentos de ensino superior. $\mathrm{Na}$ Universidade

\footnotetext{
${ }^{5}$ Nas páginas 8 e 9, aqui referidas, o autor traça uma síntese dos antecedentes históricos da pós-graduação entre nós, em estreita associação com os marcos principais da criação do nosso sistema universitário.

${ }^{6}$ BASTOS, Jésus de Alvarenga, Pós-Graduação no Brasil, op. cit. p. 9. Breve referência à estada da chamada missão francesa na USP, nos anos 1930, um dos temas mais interessantes da história da história no Brasil e que vem sendo retomado de novas perspectivas nos últimos anos.

${ }^{7}$ PAIM, Antônio. A UDF e a ideia de universidade. Rio de Janeiro: Tempo Brasileiro, 1981. À página 31 o autor pôs em relevo o fato de que o ano letivo de 1936, na UDF, foi aberto com diversas conferências de membros da Missão Universitária Francesa; CUNHA, Luiz Antônio. A universidade temporã: o ensino superior da colônia à Era Vargas. Rio de Janeiro: Civilização Brasileira; UFC, 1980. p. 245-247.

${ }^{8}$ O art. 9o da Lei no 3.998 , de 15 de dezembro de 1961, que criou a Universidade de Brasília, fixou a pós-graduação entre as atribuiçóes dos Institutos Centrais e das Faculdades profissionais.
} 
de Brasília, a pós-graduação consta como uma das atribuições dos Institutos Centrais e das Faculdades Profissionais.?

Cursos de mestrado e doutorado foram criados nos inícios dos anos 1960 em várias instituiçôes isoladas de ensino superior, de tal modo que em 1965 contavam-se já no país cerca de vinte mestrados e dez doutorados. ${ }^{10}$ Poucas universidades, predomínio de instituiçóes isoladas. Tudo levava a crer então que um leque de possibilidades e experiências inovadoras estava ao alcance das instituiçôes universitárias, uma vez que eram bastante variados os modelos e as propostas então em discussão. Entretanto, há um divisor de águas que não poderíamos ignorar: o golpe militar de 31 de março de 1964. A partir da instalação do regime autoritário não haveria mais o que discutir.

Em 1965, o Parecer no 977/65, de autoria de Newton Sucupira, atendendo a uma solicitação do ministro da Educação ao presidente do Conselho Federal de Educação (CFE), definiu de uma vez por todas o que deveria ser a pós-graduação, fixando-lhe natureza e objetivos. Tinha origem então o discurso sobre a institucionalização da pós-graduação, inserida no relatório do Grupo de Trabalho incumbido de preparar a Reforma Universitária pelo Decreto-Lei no 62.937 de 2 de julho de 1968.

Entre 1964 e 1968 foram encaminhadas as decisōes referentes às principais questôes então presentes no ensino superior: a do modelo de universidade, a da natureza e estrutura dos cursos de pós-graduação, e a do controle político-ideológico sobre os corpos docentes e discentes.

A primeira dessas questôes teve como pano de fundo a influência norte-americana, consubstanciada no "Plano Atcon" e nas medidas para controlar as atividades estudantis constantes do "Relatório da Comissão Meira Mattos”.

São dessa mesma época as medidas tomadas pelo governo para reestruturar os currículos do ensino

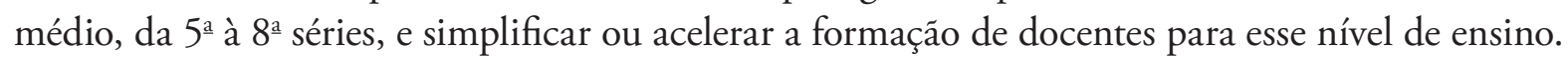

Assim, em boa parte como decorrência da influência do chamado Ponto $I V$ dos acordos com os Estados Unidos (MEC-Usaid), no âmbito da Aliança para o Progresso, foi criada uma nova disciplina intitulada de Estudos Sociais, que deveria reunir as disciplinas de História e Geografia, assim como as chamadas licenciaturas curtas. Implantou-se, ainda, uma nova disciplina, Educação Moral e Cívica, tendo como contrapartida, em nível superior, a disciplina de Organização Social e Política do Brasil (OSPB). Programas especiais, como o Premen, foram implantados a fim de agilizar o processo de formação de docentes necessários às novas diretrizes do ensino médio.

Nos Anais dos simpósios nacionais organizados pela Anpuh no final dos anos 1960 e ao longo dos anos 1970 há inúmeros debates e pronunciamentos dos docentes de História contra a introdução de Estudos Sociais e a implantação das chamadas licenciaturas curtas.

Estes temas já contam com uma extensa bibliografia e seria um tanto sem sentido entrarmos agora nessa discussão acerca das influências norte-americanas no processo de reforma da universidade brasileira. ${ }^{11}$

\footnotetext{
9 "A ideia da pós-graduação como tarefa normal e permanente da universidade, constituindo sistema de cursos regulares que visam o aprofundamento da formação recebida na graduação e conduzem a graus acadêmicos, foi objetivada, pela primeira vez no Brasil, no projeto da Universidade de Brasília. Esse tipo de pós-graduação corresponde à própria concepção da nova universidade, projetada nas mesmas bases dos centros de ensino e de pesquisa que estáo revolucionando o mundo moderno". SUCUPIRA, Newton. Antecedentes e primórdios da pós-graduação. s.n.t. 19 p. Mimeografado, apud BASTOS, Jésus de Alvarenga. Pós-graduação no Brasil, op. cit. p. 9-10.

10 "A pós-graduação analisada sob os aspectos legais mereceu da Lei de Diretrizes e Bases da Educação Nacional (Lei 4.024, de 20-12-1961) novas formulação conforme consta de seu artigo 69.” BASTOS, Jésus de Alvarenga. Pós-graduação no Brasil, op. cit. p. 11.

${ }^{11}$ COUTINHO, Afrânio. Universidade, instituição crítica. Rio de Janeiro: Civilização Brasileira, 1977; FÁVERO, Maria de Lourdes de A. A universidade brasileira em busca de sua identidade. Petrópolis: Vozes, 1977; FÁVERO, Maria de Lourdes de A. A UNE em tempos de autoritarismo. Rio de Janeiro: Ed. UFRJ, 1995; FORACCHI, Marialice M. O estudante e a transformação da sociedade brasileira. São Paulo: Cia. Editora Nacional, 1977; FERNANDES, Florestan. Universidade brasileira: reforma ou revolução? São Paulo: Alfa-Ômega, 1975; SCHWARTZMAN, Simon. Formação da comunidade
} 
A segunda questão refere-se à adoção/imposição de um modelo único de pós-graduação, num estilo tipicamente iluminista e que representou, na prática, o esquecimento/ocultamento das condiçóes que levaram à supressão de todos os demais caminhos historicamente possiveis. Também aqui se trata de um tema que já tivemos oportunidade de analisar sob dois enfoques: a pós-graduação como objeto histórico e a pós-graduação hoje. ${ }^{12}$ Por ora, talvez o que mais importa seja termos sempre em vista a genealogia dessa pós-graduação que aí está, devidamente institucionalizada.

A descrição sumária da implantação da pós-graduação entre nós, ou a sua institucionalizaçâa, talvez náo nos permita perceber, de uma perspectiva crítica, o quanto o encerramento dos debates e a definição autoritária de um modelo único de pós-graduação suprimiram, na prática, todo um leque de possibilidades. Praticamente ausentes as instâncias acadêmicas docentes e discentes, coube aos espíritos iluminados suprimir as diferenças e eliminar de fato os "futuros possíveis", para utilizarmos um conceito fundamental de Walter Benjamin. Das possibilidades ignoradas ou apagadas surgiu o mito das origens da pós-graduação como algo uniforme, consensual e historicamente necessário.

O controle político-ideológico sobre professores e alunos das universidades foi talvez a face mais ostensiva e violenta da imposição do poder autoritário sobre as atividades acadêmicas e intelectuais. Sobre tal assunto existe hoje uma extensa bibliografia. Naquilo que ele nos interessa mais diretamente, faremos algumas referências ao tratarmos da nossa memória dos anos de chumbo. ${ }^{13}$

\section{B. Memória de historiador}

Nossa memória dos anos 1960, no âmbito de nossas atividades docentes na FNFi, junto à cadeira de História Moderna e Contemporânea, aparece sempre constituída de lembranças as mais variadas. Uma constante é a lembrança do 31 de março de 1964 como um divisor de águas. Antes dessa data, vivíamos na expectativa de grandes mudanças, em meio a um clima de intensa agitação política e acadêmica. A UNE, empenhada na luta pela reforma universitária, promoveu agitados congressos em 1961, 1962, e 1963. ${ }^{14}$ A Faculdade Nacional de Filosofia transformou-se num autêntico caldeirão de lutas e enfrentamentos político-ideológicos, quer entre seus alunos, quer entre a maioria do corpo docente. ${ }^{15}$

Professores e estudantes de história também se mobilizaram. Os estudantes de cursos de graduação em história de algumas universidades do Sudeste criaram Centros de Estudos de História e reuniram-se em vários congressos, com o objetivo de discutir o ensino de história então dominante em

cientifica no Brasil. Sáo Paulo: Editora Nacional; Finep, 1979; GRUPO DE TRABALHO PARA A REFORMA UNIVERSITÁRIA. Relatório final. Revista Brasileira de Estudos Pedagógicos, v. 50, n. 111, p. 119-175, 1968.

${ }^{12}$ FALCON, Francisco J. Calazans. Depoimento: a pós-graduação como objeto histórico. Revista Maracanan, Rio de Janeiro, ano I, n. 1, p. 118-133, 1999-2000. Trata-se de um texto no qual desenvolvemos uma análise dos chamados vícios de origem do atual sistema de pós-graduação bem como suas implicações específicas para os programas da área de história, problemas que só fizeram se agravar nestes últimos doze anos.

${ }^{13}$ Convém ainda salientar, como afirma Schwartzman (Formação da comunidade científica no Brasil, op. cit.), que: "os novos programas de pós-graduação foram também prejudicados pelo clima político depois de 1968. Entre 1969 e 1970 várias dezenas dentre os mais talentosos cientistas brasileiros foram afastados compulsoriamente de suas posiçóes de ensino e pesquisa, sendo levados, em muitos casos, a deixar o país... A ocorrência destas puniçóes políticas no momento em que os novos programas de pós-graduação se criavam colocou-os sob justificável suspeita para grande parte da comunidade científica e universitária do país e fez com que muitos deles se vissem despojados de suas lideranças intelectuais quando elas seriam, supostamente, mais necessárias" (p. 298), apud BASTOS, Jésus de Alvarenga, Pós-Graduação no Brasil, op. cit. p. 34.

${ }^{14}$ FAVERO, Maria de Lourdes de A. Da universidade modernizada à universidade disciplinada: Atcon e Meira Mattos. São Paulo: Cortez; Autores Associados, 1991. Da mesma autora foram publicados na Série Estudos do Proedes/UFRJ cerca de cinco trabalhos sobre diversos aspectos da universidade brasileira a partir de uma perspectiva crítica e atual.

${ }^{15}$ ARMONY, Miguel. A Faculdade Nacional de Filosofia nos anos 1962-1964. Rio de Janeiro: Revan, 2002. 
seus métodos e orientação teórico-metodológicas. Nesse panorama de mobilização e reivindicações, destacou-se a publicação, entre 1958 e 1963, do Boletim de História pelos alunos de História da FNFi. ${ }^{16}$ As principais reivindicaçôes de então eram a atualização curricular, a modernização de métodos docentes, a atualização bibliográfica com a inclusão de autores nacionais e estrangeiros de campos teóricos variados ou mais de acordo com as novas tendências historiográficas vindas principalmente da França.

O movimento dos professores de história teve como marco fundador a realização em 1961, pela Faculdade de Letras de Marília (São Paulo), de um encontro destinado à discussão do currículo de história fixado pelo Conselho Federal de Educação. Tal evento, posteriormente denominado de I Simpósio dos Professores Universitários de História, culminou na criação da Associação dos Professores Universitários de História (Apuh), mais tarde transformada em Anpuh. Os Simpósios da Anpuh foram realizados com certa regularidade: 1962, 1965, 1967, 1969, 1971... Contando com a presença de numerosas plateias de estudantes de história, esses eventos caracterizaram-se por discussôes sobre temáticas específicas, às quais se acrescentaram, depois, problemas de didática da história e o arrolamento de fontes históricas. ${ }^{17}$

$\mathrm{Na}$ esfera específica da cadeira de História Moderna e Contemporânea estes foram anos de grandes avanços e de muitas expectativas. No final dos anos 1950, a partir do estreitamento de nossas relaçóes com os professores da cadeira de História Moderna e Contemporânea da USP, iniciado em 1958, resolvemos redefinir nossas prioridades e objetivos: priorizar os cursos e leituras sobre história da África e organizar um projeto de pesquisa razoavelmente amplo, de modo a dele participarem professores e alunos. O tema escolhido foi "O Atlântico luso-afro-brasileiro no séc. XVIII", com ênfase nas pesquisas sobre o movimento mercantil nos portos do Rio de Janeiro, Salvador e Recife. A partir de 1961, com recursos concedidos pelo Conselho de Pesquisa da Universidade Federal do Rio de Janeiro (UFRJ), demos início às nossas pesquisas no Instituto Histórico e Geográfico Brasileiro (IHGB). Ao lado do ensino, desenvolvia-se agora a pesquisa, uma vez que havia também bolsas para certo número de monitores de pesquisa do corpo discente.

No segundo semestre de 1963, atendendo a convite de alguns alunos e ex-alunos, concordamos em assessorar o trabalho de um grupo de estudantes de história que estavam então no Instituto Superior de Estudos Brasileiros (Iseb), elaborando, sob a direção do professor general Nelson Werneck Sodré, o projeto de uma "História nova do Brasil", dividida em vários pequenos volumes temáticos. Infelizmente, porém, a publicaçáo dos cinco primeiros volumes ocorreu quase às vésperas do golpe militar de 31 de março de 1964. À irritação provocada entre os setores mais conservadores da historiografia brasileira pelas abordagens típicas dos volumes da "História nova" veio somar-se então, a partir de abril, a repressão aos subversivos, entre os quais, é claro, se contavam os "historiadores do Iseb". ${ }^{18}$ Aqui lembramos esse episódio apenas com o intuito de compor com mais exatidáo as diferentes nuances daqueles anos.

Após o 31 de março de 1964, nossas lembranças são múltiplas e um tanto contraditórias. De fato, o dia seguinte foi de completo caos. Retornamos à FNFi, eu e o professor Hugo Weis, mais de uma semana depois, e encontramos nosso pequeno gabinete, no quinto andar, revirado e saqueado, após a invasão do prédio da Faculdade Nacional de Filosofia, no dia 31 de março, por tropas da Aeronáutica.

\footnotetext{
${ }^{16}$ PEREIRA, Daniel Mesquita. Boletim de História. Uma experiência de vanguarda na Faculdade Nacional de Filosofia 1958/1963. Dissertação (mestrado) — Departamento de História, Pontifícia Universidade Católica do Rio de Janeiro, Rio de Janeiro, 1998.

${ }^{17}$ FALCON, Francisco J. Calazans. A historiografia fluminense a partir dos anos 1950/1960: algumas direçóes de pesquisa. In: GLEZER, Raquel (Org.). Do passado para o futuro. Edição comemorativa dos 50 anos da Anpuh. São Paulo: Contexto, 2011. p. 13-68; GLEZER, Raquel. Memória e história. A Fundação da Anpuh. In: SIMPÓSIO NACIONAL DE HISTÓRIA, XXVI, 2011, São Paulo. Anais... São Paulo: Anpuh, 2011. Anais Eletrônicos. Conferências.

${ }^{18}$ SANTOS, Joel Rufino et al. História nova do Brasil. 1963-1993. São Paulo: Loyola, 1993.
} 
A cadeira de História Moderna e Contemporânea estava em crise: a professora Maria Yedda, escondida em lugar desconhecido, fugindo à perseguição implacável de Eremildo Luiz Vianna e seus auxiliares, agora donos da Rádio do Ministério de Educação e Cultura, só retornaria à Faculdade alguns meses mais tarde. Replanejamos os cursos, mantivemos a bibliografia fixada anteriormente, avaliamos com quem poderíamos contar, inclusive da UFF, e conseguimos levar adiante os cursos das disciplinas subordinadas à cadeira de História Moderna e Contemporânea.

A partir de 1965 as coisas foram readquirindo alguma normalidade, apesar dos vários IPMs envolvendo a professora Maria Yedda. Mesmo assim éramos otimistas. O projeto de pesquisa fora para o espaço, mas continuamos a pesquisar por nossa conta, nós, os docentes da cadeira. No meu caso, por exemplo, eram os primeiros passos da futura tese de doutorado (livre-docência) sobre o mercantilismo no tempo do marquês de Pombal. Passamos a contar com a participação do professor Ciro Flamarion Cardoso, da professora Berenice de Oliveira Cavalcante e de outros ex-alunos. Infelizmente, Arthur Bernardes Weiss veio a falecer no final de janeiro de 1965. O professor Fernando Sgarbi Lima continuou a colaborar com a cadeira e assim pudemos prosseguir nossas atividades sem maiores perturbaçóes.

Passado o susto, o movimento estudantil começou a reorganizar-se, sobretudo com passeatas cada vez mais concorridas pelas ruas do Rio. Era a época de uma intensa mobilização de protesto através de eventos culturais; os festivais da MPB, os espetáculos teatrais etc. Nós também, sob o incentivo da professora Yedda, realizamos nosso protesto através de uma espécie de tertúlias intelectuais, aos sábados, em 1967, na casa da professora Yedda, para discutirmos, em grupo, temas que estavam na ordem do dia e também alguns autores cujas obras começavam a se tornar novos e importantes desafios intelectuais: Michel Foucault, Louis Althusser, Nikos Poulantzas, Jacques Rancière, entre outros. Em 1968 teve início um programa de leituras e debates de textos de Marx.

Já mencionamos de que forma o governo militar equacionou a questão da Reforma Universitária e a da pós-graduação. Precisamos somente, para concluir esta parte de nosso trabalho, abordar ainda dois pontos: a Reforma da Universidade do Brasil e as vicissitudes do recém-criado Instituto de Filosofia e Ciências Sociais em 1967.

Ainda em 1963 tinham sido aprovadas, pelo Conselho Universitário da Universidade do Brasil, "Diretrizes para reforma da Universidade do Brasil" resultantes do trabalho desenvolvido desde 1962, pelo Escritório de Planejamento da Reforma da Universidade do Brasil (Eprub), posteriormente submetido à Comissáo de Reforma, a qual elaborou o documento que contém aquelas diretrizes. Começava então a se implementar o chamado Plano Kafuri, do qual resultaram, em março de 1967, os textos básicos da reforma da antiga Universidade do Brasil. Em 29 de julho de 1965, o Conselho Universitário da UB pronunciou-se com veemência contra a medida anunciada pelo governo de uniformizaçáo da denominação das universidades e escolas técnicas federais. O protesto náo impediu que em 20 de agosto do mesmo ano fosse sancionada a Lei no 4.759, dispondo que "as Universidades e Escolas Técnicas Federais da Uniáo, vinculadas ao MEC, sediadas nas capitais dos Estados, serão qualificadas de federais e terão a denominação do respectivo Estado”. Em 5 de novembro de 1965, a Lei no 4.831 dispôs sobre as denominaçóes das universidades federais situadas nas cidades do Rio de Janeiro e Niterói, subordinadas ao MEC, e que passariam a denominar-se, respectivamente, UFRJ e UFF.

Em 1967, dois decretos-leis instituíram o sistema departamental e criaram o IFCS. Em 28 de novembro de 1968 a Lei no 5.540 extinguiu a cátedra nas instituiçóes de ensino superior brasileiras, ao passo que em 11 de fevereiro de 1969 o Decreto-Lei no 464 instituía a Reforma Universitária. Nesta mesma data, o Parecer no 77/69 fixou normas para o credenciamento dos cursos de pós-graduação, aprovado pelo CFE.

O IFCS foi criado em 13 de março de 1967, pelo Decreto-Lei no ${ }^{\circ} 6.455$, sendo designado como seu diretor pro tempore o professor Djacir Menezes. A transferência dos cursos de História, Ciências Sociais 
e Filosofia processou-se no segundo semestre de 1967. De acordo com o Plano de Reestruturação da UFRJ, a Faculdade Nacional de Filosofia deixou de existir, substituída por vários institutos. Os cursos de História, Ciências Sociais e Filosofia foram reunidos no Instituto de Filosofia e Ciências Sociais e transferidos para o prédio da rua Marquês de Olinda, em Botafogo, onde até então funcionara o Instituto de Ciências Sociais. Teve início então, no segundo semestre de 1967, a difícil tarefa de organizar o novo Instituto, a começar pela discussão de seu Estatuto e Regimento Geral. Dado o clima político entâo dominante no Rio de Janeiro, as divergências ideológicas entre docentes e também entre alunos traduziam-se em constantes provocações, ameaças, inclusive práticas terroristas, como foi a explosão de um petardo junto a uma árvore na parte da frente do Instituto (notícia do Jornal do Brasil, em 4 de outubro de 1968: "Bomba caseira explode de madrugada no jardim do Instituto de Filosofia"). Coube à professora Marina São Paulo Vasconcellos dirigir com muita coragem e determinação os rumos do IFCS durante esses meses difíceis. Não faltaram provocaçôes jornalísticas da direita denunciando a presença e a ação de agentes subversivos entre os alunos e professores do IFCS. Em 3 de setembro de 1968, o jornal O Globo noticiou: "Terror cultural na filosofia", "Professor da UFRJ denuncia terror cultural". Notas desse tipo repetiram-se nos dias seguintes, e no dia 10 de setembro as acusaçóes se estendiam à geografia: "Terror Cultural: alunos humilham e expulsam catedrática", mantendo-se o noticiário ao longo de vários dias. Diante desses fatos, a diretora do IFCS, professora Marina São Paulo Vasconcellos, designou uma comissão de apuração para averiguar a real natureza e procedência de fatos veiculados pela imprensa, ouvindo as partes interessadas. Sob a presidência da professora Eulália Maria L. Lobo, nós e a professora Stella Amorim ouvimos durante várias semanas tanto os professores citados quanto os alunos das diversas turmas envolvidos nas denúncias. Nosso relatório final, contrário à veracidade das denúncias veiculadas pela imprensa, só foi concluído às vésperas da edição do AI-5, em dezembro de 1968.

Nosso pedido de afastamento do país fora aprovado no dia 17 de outubro. Com o AI-5, a emissão do nosso passaporte pelo Itamaraty foi vetada, incluída numa longa lista de proibiçóes. Passamos os meses seguintes, de dezembro a março, negociando com as autoridades policiais e militares a expedição de um passaporte comum. Finalmente, no final de março de 1969, conseguimos viajar para Lisboa, com uma bolsa de estudos concedida pelo Instituto para a Alta Cultura, órgão do governo português. Em maio, já em Lisboa, lemos em jornais brasileiros as notícias sobre cassaçôes e aposentadorias de inúmeros colegas e amigos, a começar por Maria Yedda, Hugo Weis e Eulália Lobo. No final de junho, quando atracou em Lisboa o navio em que Maria Yedda e José Linhares viajavam para a França, passamos um dia matando saudades. Somente anos depois iríamos nos reencontrar. Na verdade, a cadeira de História Moderna e Contemporânea deixara de existir.

\section{Segunda Parte: Caminhos e descaminhos da construção de uma Pós-Graduação EM História}

\section{A década de 1970: "Os anos de chumbo"}

Retornamos ao IFCS em dezembro de 1969, quando já estava instalado em sua nova sede, no prédio da antiga Escola Politécnica, no largo de São Francisco, no centro do Rio de Janeiro. Relembrar aqueles anos é algo um tanto difícil já que foi uma época durante a qual fizemos o possível para ficar o mais longe ou o menor tempo possível nas dependências do IFCS.

Nossa narrativa desdobra-se novamente, a partir de agora, em dois níveis: o documental e o pessoal ou memorialístico. 
O nivel documental apoia-se nas informaçóes numerosas e variadas reunidas pelos integrantes da comissão organizadora das comemoraçóes dos setenta anos do curso de História da Universidade do Brasil (1939-2009); "Memória e celebraçôes dos setenta anos do curso de História da Universidade do Brasil”, trabalho realizado sob a coordenaçáo do professor doutor José Murilo de Carvalho. A documentação assim reunida é constituída de vários anexos e nos oferece uma quantidade expressiva de dados sobre os mais diversos aspectos do curso de História, como, no Anexo I, sobre as reunióes da Congregação do IFCS. Na impossibilidade total em que nos encontramos de analisar os vários anexos que constituem a documentação reunida pela Comissão dos 70 Anos, sublinharemos apenas as observaçôes constantes do Anexo 3: "a passagem da 17ª reuniáo da Congregação do IFCS para a 18a guarda algumas peculiaridades que merecem ser relatadas". Segundo o citado documento, "A ordenação das

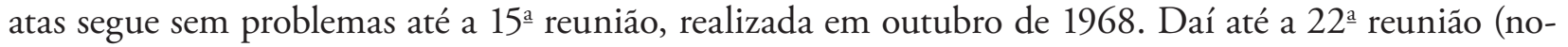
vembro de 1970), e somente neste intervalo, as folhas das atas estavam dispostas no livro numa ordem completamente aleatória. Coincidentemente ou não, durante este periodo ocorrem importantes mudanças em relação ao corpo docente, à estrutura administrativa do IFCS no que diz respeito à sua Direção e seu quadro de funcionários e também em seus regulamentos (grifo nosso). A numeração das atas segue até a 17ª reunião, de fevereiro de 1969 . Cronologicamente, não há uma ata número 18 . A reunião posterior à 17 a foi realizada em setembro de 1970 - uma reunião para eleição de uma lista sêxtupla para indicação dos nomes à escolha do presidente da República para direção do IFCS. Não sabemos o que de fato aconteceu entre fevereiro de 1969 e setembro de 1970 (grifo nosso)":

- Até a 17a reunião, a direção do IFCS era ocupada por Marina São Paulo de Vasconcellos. Depois, não é possível saber, pela análise das atas, o que aconteceu entre fevereiro de 1969 e setembro de 1970 que tenha ocasionado a mudança dos parâmetros de escolha da direção do IFCS;

- O corpo docente que integra a $17^{a}$ reunião é completamente diferente do grupo de professores que participam desta reunião em setembro de 1970 para a votaçáo de uma lista sêxtupla. Seja como for, esta seria a partir de então a situação dominante no Departamento de História.

É preciso termos em mente que vivíamos um período extremamente delicado do ponto de vista político-institucional. Além disso, de acordo com depoimentos de professores que faziam parte do IFCS na época, esse seria o período de maior turbulência para o funcionamento das atividades acadêmicas no IFCS. Nós aqui apenas afloramos a superfície dos acontecimentos. Há ainda muita coisa a analisar. ${ }^{19}$

Mas voltemos à nossa memória e suas lembranças.

Recordar os anos 1970 significa algo assim como mergulhar em águas escuras e sujas de uma época que bem gostaríamos que jamais houvesse acontecido. Difícil esquecer aqueles anos, triste e complicado relembrá-los. Circunstâncias e experiências pessoais se misturam a acontecimentos mais gerais e vivências institucionais. ${ }^{20}$

Ao retornarmos ao IFCS, em começos de 1970, pouco depois da sua mudança para o velho prédio da antiga Escola Politécnica no largo de Sáo Francisco, seu diretor era o professor Eduardo Prado de Mendonça, e o chefe do Departamento de História, o professor Eremildo Viana.

Na primeira reuniáo do Departamento de História a que comparecemos, em 1970, percebemos sem muito esforço o quanto o quadro docente havia se modificado em consequência das cassaçôes e

\footnotetext{
${ }^{19}$ O Programa de Estudos e Documentação Educação e Sociedade (Proedes), da UFRJ, possui uma documentação muito importante sobre a antiga Faculdade Nacional de Filosofia, quer sob a forma de documentos arquivados, quer em termos de publicaçôes. São várias "Séries" e seu estudo e análise acrescentariam certamente muitos dados a esta nossa exposição. ${ }^{20}$ WERNECK DA SILVA, J. L. A deformação da história, ou Para não esquecer. Rio de Janeiro: Zahar, 1985. Este livro faz parte de uma coleção intitulada "Brasil: os anos de autoritarismo. Análise, balanço, perspectivas". Em $A$ deformação da história o professor José Luiz Werneck da Silva baseou-se em numerosos depoimentos de intelectuais fluminenses, em sua maioria professores e historiadores. Também: MOURA CASTRO, Cláudio. Ciência e universidade. Rio de Janeiro: Zahar, 1985.
} 
aposentadorias compulsórias de 1969. Sentíamo-nos, nós e o professor José Luiz Werneck da Silva, como sobreviventes pré-históricos.

De 1970 a 1978 vivemos num clima de insegurança, receio e vigilância. Houve alunos que simplesmente sumiram; nossas aulas eram ostensivamente vigiadas por funcionários da limpeza; nosso nome foi vetado para uma formatura. Procuramos manter, na medida do possível, uma espécie de low profile. Foi um tempo durante o qual tive o prazer de lecionar para algumas turmas excelentes, com alunos não raro fora de série, e, apesar de tudo, continuei a usar a bibliografia com autores marxistas nos cursos de História Moderna e Contemporânea, mesmo sabendo da presença de espióes. Lecionei também a História dos Países Ibéricos. Aproveitei também, não o nego, de todos os recursos legais para licenciar-me durante vários períodos: licença-prêmio e licença sem vencimentos.

Minha atenção principal estava então voltada para a elaboração da tese de livre-docência, afinal concluída em 1975 e defendida na UFF em 1976. Já nessa época, a professora Maria Yedda retornara ao Brasil e começara a coordenar o Programa de Mestrado em Desenvolvimento Agrícola, no Horto, sob o patrocínio do Ministério da Agricultura e da Fundaçáo Getulio Vargas. Tivemos oportunidade de participar de algumas atividades desse Programa, especialmente a pesquisa sobre a "História político-administrativa da agricultura brasileira", coordenada pela professora Eulália Lobo, assim como do Seminário Internacional realizado em 1978.

Enquanto isso, fora criado, em 1970, no IFCS, um Curso de Extensão e Aperfeiçoamento em História, referido então, por alguns de nossos colegas, como Curso de Mestrado. A consulta que fizemos ao material sobre esse curso, existente na já citada documentação reunida pelo Projeto "Memória e celebraçóes dos setenta anos do Curso de História da Universidade do Brasil", permitiu-nos perceber a existência de muitos diários de classe anuais, trabalhos realizados pelos alunos para disciplinas oferecidas pelo Curso de Aperfeiçoamento, assim como os nomes das disciplinas e seus respectivos docentes. Tais cursos foram regulamentados pelo Conselho de Ensino para Graduados (CEPG) em 1971. Tratava-se de um curso heterogêneo, cuja grade curricular era bastante aleatória. Existem trabalhos produzidos pelos alunos de Aperfeiçoamento, mas não existem dissertações defendidas antes da reformulação e criação efetiva do Curso de Mestrado em 1979-1980.

\section{Afinal, o Curso de Mestrado em História}

No final dos anos 1970, mais exatamente em 1978-1979, chegamos, enfim, à saída do longo túnel. Eleita para a Chefia do Departamento de História, a professora Philomena Gebran lançou-se com determinaçáo à tarefa de reestruturar o Curso de História e o funcionamento do nosso Departamento. A participação estudantil voltou a ser um elemento importante nas deliberaçóes e decisóes. Começa também o processo de rediscussão e regulamentaçáo do Curso de Aperfeiçoamento com o objetivo de estruturar e regulamentar um autêntico Curso de Mestrado. Em 1979, com a Lei de Anistia, o Boletim Especial das Associaçóes Docentes do Rio de Janeiro publica a lista de docentes da UFRJ atingidos por atos de exceção. Dela constam os nomes de antigos professores da FNFi/IFCS, alguns, infelizmente, já falecidos. Em junho de 1979, uma manifestação pela reintegração dos professores cassados foi promovida pela Associação de Docentes da UFRJ.

O Curso de Mestrado, no processo de reformulação do antigo Curso de Aperfeiçoamento, foi dividido em duas áreas de concentração: História do Brasil e História Antiga (Roma) e Medieval. A professora Eulália L. Lobo assumiu a coordenação da pós-graduação e deu início ao processo de seu credenciamento, cuidando também, com muita dedicação e competência, da biblioteca setorial. 
Após uma visita realizada por uma comissão da Capes, o Curso de Mestrado foi finalmente reconhecido e credenciado em 1982.

\section{A fase do mestrado}

Com as mudanças implementadas a partir de 1978-1979, já agora respirando os ares benfazejos da anistia, multiplicaram-se as matrículas no mestrado e a oferta de disciplinas pelos docentes. Oferecemos vários cursos, até o final de 1983, no âmbito da história das ideias, com ênfase nas leituras e debates sobre as relaçóes entre história e linguagem.

Segundo o "Catálogo de dissertações e teses do Programa de Pós-Graduação em História Social da Universidade Federal do Rio de Janeiro - 1980-1996”, organizado pela professora Miridan Britto Knox Falci, até 1984 foram aprovadas catorze dissertaçóes de mestrado, das quais participamos das bancas examinadoras de duas delas. A professora Maria Yedda começava já a favorecer, como orientadora, estudos sobre pequenas propriedades fundiárias e formas de exploração da mão de obra no campo, enfocando sobretudo as relaçóes náo capitalistas. De tal perspectiva, constitui hoje um marco a dissertação de João Luís Ribeiro Fragoso: Sistemas agrários em Paraíba do Sul (1850-1920): um estudo de relaçôes não capitalistas de produção, defendida em 1983.

Durante o ano de 1984 estivemos no exterior, em Lisboa, com bolsa de pós-doutorado da Capes, realizando pesquisas em arquivos portugueses sobre a Intendência Geral de Polícia à época de d. Maria I, e sobre os periódicos portugueses a partir da Revolução Vintista (1820). Durante esse período foram aprovadas quatro dissertaçóes de mestrado.

Em 1985 e 1986 voltamos ao trabalho no curso de mestrado, tomando parte em algumas bancas de dissertação. Oferecemos alguns cursos semestrais no campo das questôes relativas às práticas discursivas e suas relaçôes com as ideologias. Entretanto, este foi um período dos mais complicados, pois, múltiplos compromissos tornaram entáo muito escassa a nossa presença no ICHF. Mesmo assim, pudemos orientar as dissertaçôes de Laurinda de Miranda Barbosa e de José Luiz de Oliveira.

Os compromissos acima referidos envolviam a participação em comitê do CNPq, em comissōes da Capes e, sobretudo, as tarefas do cargo de pró-reitor de Pesquisa e Pós-Graduação da UFF, de 1986 a 1990.

Julgamos importante lembrar aqui a realizaçáo do I Encontro de Professores de História do Rio de Janeiro, entre 26 e 30 de setembro de 1983, pelo Departamento de História do IFCS (UFRJ). Nessa ocasião, foram apresentados vários textos originais, tanto sobre o ensino de graduação como o de pós-graduação, bem como a respectiva inter-relaçáo. Infelizmente, até onde pudemos averiguar, os textos, inclusive o nosso, não chegaram a ser publicados.

No Catálogo de dissertaçôes organizado pela professora Miridan Knox Falci, o volume de trabalhos defendidos é impressionante, indo da página 51 à 139, de 1990 a 1995, num total de 98 dissertaçôes.

\section{A fase do doutorado}

Ao retornarmos ao IFCS, em dezembro de 1990, após nos aposentarmos na UFF, as expectativas convergiam no sentido da criação do Curso de Doutorado em História. A Coordenação do Programa de Pós-Graduação nomeou uma comissão departamental com a incumbência de propor e discutir a organização de um Curso de Doutorado, inclusive o respectivo regulamento. Deveria também ser estudada e encaminhada uma reestruturação do Curso de Mestrado. Ficamos com o encargo de relator dos debates e propostas e com a missão de redigir os documentos finais. 
Tivemos então numerosas reuniôes durante as quais se processaram discussóes longas e agitadas, fruto das muitas divergências teóricas e pessoais então existentes, de tal maneira que o processo só foi concluído em 1992: autorização do CEPG em reunião de 10 de abril de 1992 e Edital da Coordenação do Programa de Pós-Graduação em História, professor Francisco Luiz Teixeira Vinhosa, de 15 de junho de 1992. A principal novidade desse edital residia na forma então adotada para o exame de seleção: "será realizado dentro das normas e dos critérios estabelecidos individualmente pelos docentes devidamente autorizados pelo Colegiado, que aprovou também o número de vagas oferecidas e a indicação da área proposta pelos referidos docentes, constantes da relação anexa". O exame, prosseguia o mesmo edital, deveria ser realizado pelos docentes examinadores individualmente, tendo caráter classificatório e eliminatório. Foram definidas duas áreas temáticas: Sociedade e Cultura, e Sociedade e Política; cada examinador poderia escolher, como critério de seleção, duas ou três formas possíveis: entrevista, análise de projeto de tese, análise de memorial. Na prática, apenas houve uma examinadora que elegeu as três formas, enquanto todos os demais optaram pela entrevista e análise do projeto de tese.

$\mathrm{Na}$ verdade, pensávamos então, muitos de nós, no sistema tradicionalmente vigente na USP. Entretanto, conforme se pôs em prática o novo sistema de seleção e admissão ao doutorado, verificou-se que era muito difícil estabelecer certa coerência entre os comportamentos dos diversos docentes em termos de critérios acadêmicos explícitos quanto à aceitação de candidatos ao doutorado. Instalou-se um crescente mal-estar entre muitos docentes, sobretudo a partir do funcionamento da Comissão de Bolsas, com a verificação de que os critérios de seleção ao doutorado tendiam a estar muito ligados àqueles estabelecidos para a concessão de bolsas. Assim, em 13 de maio de 1994, a Comissão de Bolsas resolveu submeter ao Colegiado cerca de seis propostas que, na verdade, tendiam a modificar radicalmente algumas das características iniciais do Curso de Doutorado: rediscutir os futuros critérios de seleçáo ao doutorado; respeito às normas vigentes que proíbem conceder bolsas a doutorandos que trabalhem na própria Universidade; criar uma Comissão Acadêmica de Avaliaçáo Periódica (anual) dos doutorandos para efeito de distribuição de bolsas, a ser instalada até 15 de julho de 1994 .

Dando sequência às propostas aprovadas em maio, o novo coordenador, professor Afonso Carlos Marques dos Santos, apresentou, em 15 de agosto, um Projeto de Resoluçáo que dava "nova redação aos Artigos 41 e 43 do Regulamento Específico do Programa" e suprimia "o parágrafo único do mesmo artigo". Em resumo, a seleção de candidatos ao doutorado passava a ser atribuição de uma Comissão Examinadora, aprovada pelo Colegiado, e constituída por cinco docentes permanentes do Programa. Tal proposta foi aprovada pelo Colegiado do Programa de Pós-Graduação em História Social na reunião plenária de 5 de setembro de 1994. Em 14 de setembro do mesmo ano foi publicado o Edital do Exame de Seleção ao Doutorado, previsto para o mês de dezembro de 1994. No mesmo edital estavam mencionadas as provas: língua estrangeira, prova escrita, exame de projeto e entrevista. Em suma, abandonava-se o sistema de seleçáo por orientador e estabelecia-se outro, talvez mais tradicional, semelhante ao do mestrado. Permaneceu apenas, da antiga concepção, a exigência do exame e homologação prévia, por uma comissão docente, dos processos de inscrição na seleção, tendo em vista a análise dos respectivos projetos de tese.

\section{Os anos 1990}

Os anos 1990 foram dos mais movimentados no Programa de Pós-Graduação em História Social. A implantação do doutorado, a entrada de novos docentes, a elaboração das primeiras teses de doutorado, tudo isso dinamizou bastante nosso cotidiano. Foi também o início de um período de querelas e rivalidades pessoais ou teóricas. Recordo-me da formação de grupos e de disputas algumas vezes veementes 
durante as reuniōes do Colegiado. Lecionei nessa época os primeiros seminários de pesquisa para os alunos de doutorado e pude assim participar de algumas teses bastante originais, além daquelas sob minha orientação direta.

Aposentei-me em meados de 1995, muito a contragosto, forçado, como tantos outros colegas, pelo clima de terror então implantado pelo MEC em termos de ameaças aos direitos dos aposentados do serviço público num futuro próximo. Continuei, porém, ainda por vários anos a manter contato com muitos dos doutorandos, orientei e participei de muitas das bancas de doutoramento do final dos anos 1990 e de começos do novo século. O mesmo poderia lembrar a respeito de nossa participação em diversas bancas de concurso público para seleção de novos docentes.

Cabe não esquecer, ainda, os diversos eventos organizados pelo Departamento de História e dos quais participamos. Assim, apenas para exemplificar, o "III Encontro Regional de História", patrocinado pelo Núcleo do Rio de Janeiro, da Anpuh, sobre Revolução e História e realizado em outubro de 1988, no IFCS; a participação no Seminário Internacional sobre a Inquisição, em 1987; assim como em eventos patrocinados pelo CNPq, em 1988 (Seminário sobre a Aboliçáo da escravidáo) e em 1989 (Seminário sobre a Proclamação da República).

\section{Fatos posteriores e lacunas que permanecem}

O presente estudo/relato termina na verdade com a nossa saída da atividade docente no IFCS. Ficam assim diversas lacunas a preencher:

- As dissertaçôes e teses posteriores a 1996;

— Os muitos eventos, comemorativos ou não, organizados no IFCS nos últimos dezessete anos;

— Os rumos do Programa de Pós-Graduação em História Social, sobretudo o reconhecimento, em 2004, do Programa de Pós-Graduação em História Comparada;

- O lançamento, no ano 2000, da Topoi: Revista de História, recentemente selecionada pela Capes como uma das mais representativas do setor no país.

Por último, nossas desculpas ao leitor pelas dimensões que este texto alcançou, embora, ainda assim, muitas coisas tenham sido deixadas de lado, principalmente aquelas reflexóes que fatalmente resultam da leitura de vários passos da nossa narrativa. 


\title{
PPGHIS, uma experiência
}

\author{
José Murilo de Carvalho \\ Universidade Federal do Rio de Janeiro \\ Rio de Janeiro, RJ, Brasil \\ josemurilodecarvalho@gmail.com
}

\section{Memórias em sequência}

Não tenho muito que dizer sobre o texto do professor Francisco Falcon porque, para meu desapontamento, não convivemos no PPGHIS. Concorri ao cargo de professor titular para o então Departamento de História da UFRJ em 1997. Logo a seguir, entrei para o Programa de Pós-Graduação em História Social. O professor Falcon aposentara-se dois anos antes. Ele viveu os anos difíceis de formação do programa, Mestrado e Doutorado. Quando entrei, o Mestrado já funcionava há 15 anos, o Doutorado há cinco. Nossas memórias não se superpóem. Antes, a minha dá sequência à dele. Para mim, a experiência foi diferente das que tive anteriormente. $\mathrm{Na}$ Universidade Federal de Minas Gerais (UFMG), fui um dos fundadores do Mestrado e Doutorado; no Instituto Universitário de Pesquisas do Rio de Janeiro (Iuperj), ajudei a criar o Doutorado. Ao entrar para a UFRJ encontrei Mestrado e Doutorado já de pé. O que posso fazer, então, nesses comentários é emendar minha memória na do professor Falcon e trazer a narrativa até 2009, quando a UFRJ me aposentou. Apesar dos riscos envolvidos na operação, opto por registrar com candura minha experiência no PPGHIS que agora celebra seus trinta anos.

\section{Tempo de estranhamento}

A primeira impressão que tive foi quase de choque. Voltava, depois de dezenove anos, a lecionar na graduação. Enfrentar de novo, em salas desconfortáveis, grandes turmas de alunos, cuja postura destoava radicalmente daquela de meus tempos na UFMG, não foi fácil. Imagino a surpresa (e talvez a hilaridade) de colegas e alunos quando pedi um microfone para me conseguir fazer ouvir na sala 200. Devo ter sido também julgado um tanto maluco quando disse a alunos faltosos ou impontuais que o ensino público náo era gratuito, era pago pelos contribuintes, inclusive pelos pais deles, e que, portanto, assim como os professores tinham obrigação de ensinar, eles tinham o dever de estudar. Aos poucos, no entanto, reconciliei-me com a graduação ao ponto de, ao final, lhe dar preferência em relação à pós-graduação. Certamente, a maior gratificação que tive na UFRJ foi receber a lista de mais de quinhentas assinaturas pedindo minha emerência encabeçada por alunos da graduação.

Quanto aos colegas, desconhecia quase todos, à exceção de alguns que conhecera como alunos no Iuperj ou como colegas na Casa de Rui Barbosa e no Cpdoc. Ao longo dos anos, desenvolvi boas relaçôes com quase todos, sobretudo com os da área de Brasil.

Na pós-graduação, continuei a ensinar pensamento social e político brasileiro, prática que iniciara na UFMG e continuara no Iuperj, em parte como reação ao forte cosmopolitismo desses programas. Em parte também porque pensamento político em geral não era tema muito valorizado em ambiente ainda marcado pelo marxismo. 
Outra surpresa que me aguardava foi a orientação intelectual predominante no Programa. Formado em Ciência Política, minha obra, desde antes da tese de doutoramento, voltara-se para a história política. O deslizamento para história fortalecera-se durante minha estada no Instituto de Estudos Avançados de Princeton (1980-1981) e nos anos de pesquisador na Casa de Rui Barbosa (1986 a 1997). Em minha visão de então, que mantenho até hoje, o estatuto epistemológico da história difere substancialmente do das ciências sociais. Foi com surpresa que me deparei com exigências para os concursos de Mestrado e Doutorado idênticas às que ajudara a formular na UFMG e no Iuperj. Lá estavam os marcos teórico-metodológicos, as definições conceituais, as hipóteses, e não só como exigência para a seleção, mas também para a feitura das dissertaçóes e teses. Predominava e, que eu saiba, ainda predomina, sem ser unânime, a visáo da história como ciência e não como parte das Humanidades. E náo se tratava da Scienza nuova de Vico. Nesse ponto, ao longo de todo o período que passei no PPGHIS, nem mudou o programa, nem mudei eu, sem que a diferença, no entanto, tivesse causado qualquer desconforto nas relaçôes com os colegas, talvez apenas alguma confusão na cabeça dos alunos. Diversidade é sempre benéfica.

\section{Tempo de procela}

Superado o estranhamento inicial, vieram dois anos, 2000 e 2002, de grandes dificuldades. A professora Francisca Azevedo, substituta, na coordenação do Programa, do professor Afonso Carlos, que assumira a coordenação do Fórum de Ciência e Cultura, buscava aprimorar as práticas administrativas. Talvez por ser novo na Casa e pela experiência anterior, insistiu em que a sucedesse no posto para continuar o trabalho. Aceitei a contragosto, por não morrer de amores por administração. Razões externas e internas tumultuaram os dois anos do mandato. De fora, havia a política restritiva do governo em relaçáo ao financiamento das universidades federais. A consequência disso foram dois anos de greves de professores e funcionários que obrigavam o coordenador a se desdobrar na luta pela manutenção das aulas na pós-graduação e a funcionar como secretário do Programa. Mas o mais doloroso foi a crise interna que culminou na saída de vários professores, reagrupados logo depois no Programa de Pós-Graduação em História Comparada. Ao tentar intermediar a disputa, fiado no fato de não ter participado das disputas internas anteriores à minha chegada, percebi que não havia como conciliar os dois partidos, táo fortes eram as animosidades recíprocas. Restava-me buscar o mal menor, que era conseguir um divórcio que pelo menos preservasse os direitos dos alunos. Foi o que se verificou, deixando, no entanto, em mim sensação amarga de derrota.

\section{Tempo de trabalho}

Passada a tempestade, vieram tempos mais amenos, tanto fora como dentro, com menos greves e menos conflitos. Testemunhei nesses anos avanços importantes no Programa. Listo apenas os que me parecem mais relevantes.

Em 2000 foi criada a Topoi. Embora achasse o nome grego pretensioso (assim como o são Phoînix, Clio e semelhantes), vi a revista firmar-se entre as melhores do país e tomar, recentemente, a corajosa decisão de se tornar eletrônica. Os grupos de pesquisa, chamados, à maneira das ciências exatas e biológicas, de laboratórios, consolidaram-se e alguns deles se tornaram referência nacional e internacional. Aumentaram os contatos internacionais. Nesse departamento, saliento a realização de seminários com participação de pesquisadores estrangeiros em que a troca intelectual se dá em mão dupla e de maneira 
igualitária, em contraste com a velha prática colonizada de buscar lá fora a "teoria" para interpretar os dados de cá dentro. Finalmente, a incorporação de novos pesquisadores rejuvenesceu o quadro docente e diversificou suas competências.

\section{Tempo de futuro}

Os avanços foram reais, como o demonstra a classificação atual do Programa pela Capes. É crucial que se mantenha o dinamismo e se enfrentem novos desafios, tanto no plano do ensino como da pesquisa. Cada um de nós terá sua lista de prioridades. Cito algumas apenas a título de ilustraçáo. Creio ser importante buscar meios de contribuir para a melhoria do ensino de história no nível médio para termos melhores candidatos ao Programa. Isso exigiria maior flexibilidade na estrutura do ensino. Acho também que a internacionalização do Programa deveria desdobrar-se no sentido da atração de alunos estrangeiros e do estudo de outros países, invertendo a lógica do brasilianismo. Impóe-se o estudo dos países hispânicos, assim como da China e da Índia. O intercâmbio internacional de professores deveria adotar a mão dupla. A visibilidade nacional do Programa, essencial para atrair bons alunos, deveria ser ampliada com novas iniciativas, tanto de professores como de alunos, à semelhança do que fazem outros programas.

São algumas divagações emerenciais que me ocorrem. 


\title{
Relendo memórias
}

\author{
Marieta de Moraes Ferreira \\ Universidade Federal do Rio de Janeiro \\ Rio de Janeiro, RJ, Brasil \\ marieta@fgv.br
}

O texto do professor Falcon pode nos conduzir a duas leituras sobre a trajetória do PPGHIS: a primeira permite acompanhar o testemunho de um ator e personagem que, através do relato de memória - marcado pela emoção e seletividade, características típicas desse tipo de depoimento —, recupera suas vivências nas lutas sobre as tentativas de empreender a profissionalização no campo da história. A segunda leitura do texto nos conduz a rever, com um olhar mais analítico e crítico, o itinerário da pós-graduação no Brasil, em geral, e no IFCS/UFRJ, em particular.

Como ex-aluno e, depois, professor da Faculdade Nacional de Filosofia da Universidade do Brasil, Francisco Falcon foi testemunha e personagem de destaque da mesma trajetória. Criado em 1939, o curso de História da Universidade do Brasil representou um momento importante do processo de profissionalização do ensino de história em âmbito nacional. Paulatinamente, o campo dos estudos históricos estava deixando de ser ocupado por profissionais liberais para formar professores especializados. No entanto, até 1964, as mudanças, inovaçôes ou permanências do curso estavam direcionadas para a formação de professores da educação básica. Embora tenha havido tentativas de elaboração de projetos para a criação de cursos de pós-graduação, as iniciativas não lograram sucesso.

Com o golpe militar de 1964, um novo momento se iniciou. Em 1965, a aprovação do Parecer no 977/65, de autoria de Newton Sucupira, definiu a natureza e os objetivos dos programas nacionais de pós-graduação. Nos anos seguintes foram encaminhadas as decisóes referentes às principais questóes relativas ao ensino superior, sendo preparadas as medidas necessárias para concretização da Reforma Universitária de 1968 e a institucionalização efetiva da pós-graduação.

Os debates e os preparativos em torno da reforma universitária, mais uma vez, iriam colocar a Universidade do Brasil e a Faculdade Nacional de Filosofia como um campo de experiência do que viria a acontecer com todas as demais escolas localizadas nos diferentes estados que se transformariam em universidades federais. A despeito das resistências contra a uniformização da denominação das universidades e escolas técnicas federais, medida anunciada pelo governo em novembro de 1965, as universidades federais situadas nas cidades do Rio de Janeiro e Niterói, subordinadas ao MEC, passariam a ser denominadas, respectivamente, Universidade Federal do Rio de Janeiro (UFRJ) e Universidade Federal Fluminense (UFF). Nesse contexto, a FNFi foi desmembrada em novos institutos, entre eles o Instituto de Filosofia e Ciências Sociais, que passaria a abrigar o curso de História, dando lugar para mudanças expressivas no campo do ensino e da pesquisa dos estudos históricos.

A despeito das enormes perdas trazidas pelo regime militar com as cassaçôes e perseguições a alunos e professores, começava a se delinear um novo modelo de curso de História, em que a pós-graduação e as atividades de pesquisa passavam lentamente a ocupar um lugar-chave. Ainda que com grandes dificuldades, em virtude das perdas sofridas, dos afastamentos compulsórios dos mais qualificados professores dos seus postos de trabalho - pois não é simples arregimentar um grupo expressivo de professores 
com experiência para estruturar um curso de mestrado —, abriam-se caminhos para definição de um novo formato do curso de História, com investimentos expressivos para estruturar a pós-graduação. ${ }^{1}$

Apesar das resistências ao novo modelo trazido pela reforma universitária e dos conflitos permanentes entre alunos, professores e autoridades do MEC, em 1970, foi implantado um curso de especialização em História, na UFRJ. Seu percurso foi conturbado com grandes dificuldades para sua legitimação, mas finalmente essa primeira iniciativa foi reconhecida como o mestrado em história social, em 1982.

Com a abertura política, o retorno da democracia no país e a volta dos professores cassados, o processo de expansão da pós-graduação ganhou uma nova dimensão. Nesse novo contexto, os estudos históricos avançaram em direção a uma maior institucionalização, com a possibilidade de desenvolvimento de novos temas para investigação e de formação de novos quadros especializados na pesquisa e no ensino universitário, fortalecendo o processo de consolidação da pós-graduação. No caso particular do Programa de Pós-Graduação em História Social (PPGHIS), os anos 1990 foram especialmente importantes com o ingresso de uma nova geraçáo de professores, o que permitiu uma reestruturação do curso de mestrado e a implantação, em 1992, do doutorado. Nos anos seguintes, o PPGHIS ingressaria numa nova fase, com um aumento expressivo da sua produção científica e sua inserção no rol dos programas de excelência na área de História.

A proposta do texto do professor Falcon não é só recuperar os itinerários percorridos pelo PPGHIS, mas destacar, com uma perspectiva crítica, que a implantação da pós-graduação foi marcada por muitas controvérsias. Nesse sentido, o encerramento dos debates e a definição autoritária de um modelo único de pós-graduação suprimiram outras possibilidades e projetos. Mas ainda assim avanços importantes foram alcançados.

Através da trajetória do professor Francisco Falcon é possível percorrer os caminhos dos processos de institucionalização do ensino universitário e de formação dos profissionais de história. Suas memórias nos mostram as diferentes conjunturas, os embates, os projetos, os conflitos, as divergências e os esforços para que o campo dos estudos históricos fosse progressivamente ocupado por profissionais com formação adequada. A leitura do seu texto nos permite ainda acompanhar as mudanças que tiveram lugar no território nada pacífico da área, com a progressiva transformação de seus cursos, de essencialmente formadores de docentes para a educação básica em direção a um novo perfil com ênfase maior para a pesquisa e a pós-graduação. Essa contribuição certamente tem um valor comemorativo neste momento do aniversário do PPGHIS, mas também oferece subsídios para pesquisas futuras.

${ }^{1}$ FERREIRA, Marieta de Moraes; MOREIRA, Regina da Luz (Org.). Capes, 50 anos. Brasília: Capes, 2002. 